\title{
Using Case Studies for Teaching Management to Computer Engineering Students
}

\author{
Ozgur Ates ${ }^{1}$ \\ ${ }^{1}$ Department of Management, Faculty of Political Science, Ankara University, Ankara, Turkey \\ Correspondence: Ozgur Ates, Department of Management, Faculty of Political Science, Ankara University, \\ 06530, Cebeci/Ankara, Turkey. Tel: 90-312-595-1373. E-mail: ates@politics.ankara.edu.tr
}

Received: November 28, 2012

Accepted: December 18, 2012 Online Published: February 16, 2013

doi:10.5539/ijbm.v8n5p72

URL: http://dx.doi.org/10.5539/ijbm.v8n5p72

\begin{abstract}
Case based learning is an important feature of business education as it enables students to discover and develop their unique framework for understanding real business situations and dealing with business problems. The objective of this paper was to show the outcomes of teaching an introductory management course to non-business students using the case methodology. The study was conducted on computer engineering students at a university in Turkey to investigate their perceptions and approaches towards case based learning. The data was collected through a survey and classroom observations. The results show that the students' active participation and discussion in class on cases increased their retention and motivation in learning the new concepts.
\end{abstract}

Keywords: business education, non-business students, case based methodology, group discussions, learning, retention

\section{Introduction}

Management education readily prepares the students to have the necessary skills to help them deal with real business situations in their work life. Teaching management should be designed and delivered with this objective in mind alongside with the learning of theoretical concepts (Chakrabarti \& Balaji, 2007).

Researches (Ates, 2012; Kvam, 2000; Myers \& Jones, 1993) state that students' active participation in the educational process increases their learning and retention. In an active, collaborative, or cooperative learning environment, students take more responsibility for their own education (Pariseu \& Kezim, 2007).

A case study describes a company's or organization's real situation and experience at a particular point in time. The case study method encapsulates a teaching methodology that has transformed traditional models of management training (Sanchis, 2007). It provides an active teaching method as well as a real and effective way that will enable a business/management student to assume a key role as a business decision maker. The case study method enables the students to gain certain skills and also understand the theoretical concepts that are necessary to make a case analysis.

There are two types of cases; those used for research purposes and those for teaching. Scientific research in any field (medicine, biology, law, sociology, business management, and so forth) uses the case study as a qualitative research methodology to illustrate a particular situation. Cases that are published in academic journals are commonly research cases in the field of business management. In teaching and education cases are used for practical and participatory learning (Sanchis, 2007).

The benefits of case study methodology have been discussed widely (Cochran, 2000; Spackman \& Camacho, 2009). One of the significant advantages of using case studies in teaching management is that it gives the students the opportunity to apply theoretical knowledge and adapt the abstract models that were taught in class to a real business problem, making them understand specific roles related to a company or organization's functions and finally engaging in interpersonal interactions with the professor or their colleagues, in order to make complex decisions (Gurau, 2010). Case study method bridges the gap between the theoretical teaching and real world practices (Asbaugh \& Kasten, 1995). Bridging this gap means that in analyzing multiple teaching case studies one can combine rich, detailed cases with large sample breadth, and hence allowing instructors to use both qualitative and quantitative methods. Another advantage is that it increases students' communication 
competence where the student is able to understand what is said about the real environment and respond with the appropriate use of the language without communication inferences (Grosse, 1998). One other advantage is that they are often longitudinal and provide insights of the circumstantial changes in a time framework (Miller \& Friesen, 1977).

Case based methodology is not widely used at universities in Turkey. This is due to the fact that most widely used research cases are published in English and there are not many cases translated into Turkish. The medium of instruction is in Turkish language in many universities in Turkey. In addition there is a limited number of Turkish language printed case study books (Ates, 2012). Therefore, instructors who use case based methodology in their classrooms predominantly use case studies in English. This becomes a limitation for students as well as instructors who are not fluent in the English language. Thus, instructors avoid using cases in their teachings.

There is limited number of studies which investigates the effectives of case based methodology in Turkish higher education classrooms. The objective of this study was to understand the effectiveness and impact of the case based methodology of non-business students in learning management theories and practices. Therefore, this study aims to contribute to the case based methodology studies in Turkey and to encourage the Turkish academia to use case based methodology more as a mode of teaching.

\section{Literature Review}

Teaching management has different methods and approaches. One of the most effective classroom teaching methods for management is the use of case studies as it relates real life business situations to theoretical concepts (Peterson \& Pratt, 2004). Business cases are used in many types of business classes and the case analysis forces students to take into account many factors that may or may not be obvious in a complex situation (Menna, 2009). As an instrument for management teaching case studies have been accepted in business schools all over the world. Case studies have a rich history for exploring the space between the world of theory and the experience of practice. It is one thing to have an idea and another thing to make that idea concrete and real (Breslin \& Buchanan, 2008).

The usefulness of case studies in teaching management theory has been questioned in academia (Shugan, 2006). But most research suggests exactly the opposite. A study conducted by Christensen and Carlile (2009) state that case studies unite the development of theory with teaching in a single enterprise that could be defined as course research. Case studies transform teaching into research, which enroll students as course researchers, whose class participation can be exceptionally valuable in the theory-building process. Case studies can be structured to display the phenomena in all its complexity which helps to comprise a solid foundation for theory building courses (Christensen \& Carlile, 2009). Students develop judgment and reasoning skills by evaluating various options and concentrate on complex problems which do not have only one right answer (Ambrosini, Bowman \& Collier, 2010). Basically, teaching cases provides a classroom substitute for experience (Garvin, 2007).

Most teaching case studies describe actual business situations, detailing some aspects of organizational life, for example a change in strategy or the behavior of a new CEO in its real world context. They are used to help students understand multiple issues in complex situations and usually include a chronology of significant events in the organization's development (Ambrosini et. al., 2010). All cases are designed for the use in classroom to help students develop an appreciation of real life management issues and thus are seen as essential in management education (Liang \& Wang, 2004).

The selection of the case materials must be considered carefully since the case study methodology is an important tool for successful business/management courses. The students should be able to understand the cases' connection with the courses teaching objectives. The case should also motivate the students so that they find the content compelling to work the case out. The complexity level of the case is also an important feature as it requires in-depth analysis of critical thinking by the student rather than having one simple answer (Jackson, 1998).

Case-based learning is now a core feature of business education programs all around the world. However there are problems that arise when this methodology is adopted in different countries. As Bogdan (2008) states most cases have an American standard, especially regarding financial statements. In his study, as an example, Bogdan significantly points out the differences of the Bucharest Stock Market and the New York Stock exchange as an example. He clearly states the differences of the management of an organization in Romania and in the United States. For Romanian students at times the cases seemed rather "unreal". Yet Bogdan argues that even under academic criticism and under pressure of alternative methods, the case methodology remains the main teaching instrument and is the best method for Romanian students. Chen, Zhao and Ding's (2009) study in China reflects a cultural matter. The case methodology aims for the students to explore the answers by themselves whereas, in 
China's traditional educational pattern, the students hope to have the information on the cases and solutions to be explicitly provided. Their research indicates that the Chinese students somewhat find the cases to be complex. However, the study states that certain objectives of the case based methodology such as cultivating students' comprehensive abilities, teamwork abilities, as well as their abilities in assessment, decision making and learning, understanding and employment of concepts have been achieved (Chen, et al., 2009).

Before discussing the findings of the study it is important to provide background on the case studies discussed in the classroom. Business cases vary from focusing on specific tools for analysis to comprehensive strategic decision-making problems (Ates, 2012). The cases were carefully chosen taking into consideration their suitability for non-business students to teach the basic principles of management. Another important factor to take into account was that English is a second language for all the students and the difficulty level of comprehension might be an issue. In addition the cases were chosen from globally well known companies to keep the interest of the students.

Each week the students were asked to read an average of two cases all specifically chosen on a management topic (i.e, on Management, managers and managing; A case in contrast-Steve Jobs, Apple, on the environment of managing; Changing ways of making cars and Fordism in practice, on managing decision making and planning; Levi's). Every week students came to class prepared having read the cases and class notes provided by the instructor on the important theories and practices. After an hour of discussing the case and main themes regarding the principles of management the students were asked to analyze the case and answer the discussion questions in class working in groups of three to four members. As we know from previous researches, business cases often require students to use teamwork as well as multidisciplinary approaches to solve business problems (Ates, 2012, Meyers \& Jones, 2007). Class discussion activities in and among small groups were expected to be a motivational factor for the students. During this process students actively engaged in the learning process.

In terms of material presentation, as suggested by Tang and Austin (2009) different types of methods were also used in class, facilitated by technologies mainly by means of powerpoint, video, the internet and lecture. A spectrum of sources such as films, web sites, newspaper, and other printed materials were used. The multimedia usage definitely motivated the students' interest and provided a more realistic business like environment. The dialectical, conversation approach of Christopher Langdell at Harvard Law School was followed, helping the students enter the conversation, rising to theory and moving to application, and then moving back to reflection. The transition to effective theory informed conversation was encouraged by the instructor hoping that the students made a stronger connection with theory that will help them with principles that they can use later in their work practice (Breslin \& Buchanan, 2008).

\section{The Study}

\subsection{Purpose of the Study}

The purpose of this study was to understand the perceptions of non-business students who were computer engineering students learning management through case based methodology. This study focuses on the students' perceptions of the case study method on management teaching, benefits, criticisms, and limitations of this approach and the impact of case study method on the students' outcomes.

\subsection{Context of the Study}

The university this study took place in is a well known one in Turkey. The university has a very strong traditional background (established in 1925). All departments except for computer engineering carry out the education in Turkish language. The computer engineering department is a fairly new department compared to the other departments at the university. The undergraduate program was initiated in fall 2003-2004 and the graduate program in spring 2004.

The faculty consists of experts in various computer engineering fields. The faculty members and the supporting academic staff are experienced in both academia and/or industry.

In order to attain a higher level of instructional quality, the department admits only a limited number of students each year (varies from eighty to a hundred). There are two undergraduate programs where in one of them all courses are in English, and in the other thirty percent of the courses are in English and the rest is in Turkish language. The admission is through the national university entrance examination, where the computer engineering students rank in the top one percent among a million students who take the exam. The computer engineering department particularly carries out their education solely in English so the students would be able to follow the world standards with their newly gained knowledge and ability. Students with limited English language skills are required to attend language preparatory school prior to starting their formal engineering education. The 
department offers non-departmental mandatory courses from other departments such as 'Introduction to Management', 'Marketing', 'Economics', 'Statistics', and so forth. In both undergraduate programs the non-departmental courses are offered in English.

This study is based on the findings of two management courses offered to the computer engineering students in spring 2012.

\subsection{Participants}

The participants of the study were 90 sophomore computer engineering students who were enrolled in the management course. The total number of students enrolled in the two courses is 118 and the number of respondents to the survey is 90 . The management course is a must course for sophomore students. It is their second non-departmental course after the economics course offered in the fall semesters. Although the course was offered as a non-departmental elective to other engineering department students, no students from other departments were enrolled in the class simply because the course was in English (as mentioned before, computer engineering department is the only department at the university whose program is in English).

In addition, the instructor of this management course also participated in this study and provided classroom observations from his/her experiences while teaching the course.

\section{Data Collection}

The data was collected in two management courses offered in spring 2012. At the end of the semester the students were asked to complete a survey voluntarily to evaluate the case based methodology for their management course.

\subsection{Questionnaire}

The survey included ten questions (see Appendix). One question referred to the demographic details and there were four questions using a likert scale item. There were three bi-polar questions (yes/no) on trying to understand if the case study method was an effective mode for teaching management to the computer engineering students. In addition, two open-ended questions, inviting comments from the students about additional insights into their views and concerns about the mode of learning using the case study method, were given at the end of the survey.

One important fact to note is, in order for students to express themselves better (by using their native language which is Turkish) the survey questions were asked in Turkish. The comments provided on the open ended questions were translated into English.

\section{Data Analysis}

The survey data were analyzed to identify the perceptions of computer engineering students towards case based methodology used in the management course. Descriptive statistics were used to analyze the survey data. Descriptive statistics was used to find and report the frequencies of each survey item. The survey also consisted of open-ended questions where thematic analysis was used. Categories and themes have emerged from the open-ended survey responses. The common responses of the students that implied the same meaning of core concepts were grouped under different themes and appropriate categories.

\section{Findings}

This section presents the findings of the quantitative and qualitative data analysis. The section starts with the results of the survey and finally the themes and issues that emerged from the open-ended questions that the students were invited to comment on are discussed.

Of 90 participants who completed the survey 29 were female and 61 male. This also shows the ratio of the students' gender distribution in the computer engineering department.

In learning the concepts, theories and practices of management $61(67.8 \%)$ students thought the case based methodology to be very useful, while $28(31.1 \%)$ students indicated that they found it somewhat useful. Only one respondent did not find the teaching methodology useful at all. In addition, 73 (81.1\%) of the respondents stated they never took a case based course before. On the other hand, 17 students noted that they did.

The survey included a question on whether the case based methodology was helpful understanding the different practices and applications in the business world by companies, $78(86.7 \%)$ respondents indicated that it was very useful. As mentioned earlier, a case study describes a real situation where a company/organization experiences at a particular point and teaches real world practices. Twelve (13.3\%) students indicated that it was somewhat useful where none of the students mentioned it to be not useful.

Meanwhile, the students were asked whether they have developed an interest in the business world and different companies' functions after completing the management course. Forty four respondents (48.9\%) indicated that 
they are now very much interested, where 40 (44.4\%) were somewhat interested and only 6 mentioned that they were not very interested.

The students were asked if they believe they have gained a new perspective and understanding of business news. Eighty five (94.4\%) respondents stated 'yes 'and only 5 (5.6\%) answered 'no'. Clearly the students were able to follow the real life activities of the world of business.

Another question was to understand whether the students would prefer a course solely based on lecturing rather than the case based learning. Eighty two (91.1\%) respondents indicated 'no' where 8 (8.95\%) mentioned 'yes'.

The students were asked to rate the top three cases they liked and were interested in studying the most. Their top pick was the 'Fordism' case incorporated with 'Changing ways of making cars' case where they learned about the management principle theories, followed by Steve Jobs, Apple case and Dell. The other cases they liked were Mc Donald's corporation in emerging markets and the Levi's case.

Furthermore, based on the data analysis the following common themes and issues emerged from the data. The themes include, students': 1) ideas on case based methodology. 2) views on cases combining theory and practice. 3) views case discussions. 4) views on class presentations. 5) language barriers.

\subsection{Ideas Based on Case-Based Methodology}

Most students found the case based methodology different than traditional lectures and supported the use of cases in learning management. They found it to be fun and mentioned that the level of retention is very high which is expected from a case based methodology course. The majority also believed that this mode of learning was more "interesting" than traditional lectures. Some of the students expressed:

This class was very different than the old traditional lecturing concept. It was definitely very efficient.

The case based learning helped me gain a new perspective on problems. I learned a lot about myself as well.

I can't think of a better method to learn management.

I hope we take classes like this in the future. After this course I can picture myself as a top manager in a high tech company.

I remember all the management concepts so well from every case that I don't think I will ever forget them. The cases always kept me interested in the course.

I always get bored in traditional lecturing classes, but with case based methodology you always have to be alert, otherwise you miss a lot of important facts. It's so much fun.

I wish it was possible that all of our classes would be case based. It's so much fun.

\subsection{Views on Cases Combining Theory and Practice}

Most students acknowledged that studying cases had enhanced their problem-solving and decision making skills and connected them to the real world of business. Below are the statements made by some students explaining this:

The case studies show us the practices in the real world. You can definitely relate the theories, practices in real companies.

All the cases were on very popular companies that we all know. It was amazing to study the difficulties they faced. I always thought the managers were clever and lucky...seems not.

Last week I saw the DHL truck and immediately thought, DHL is FedEx's largest competitor with UPS. Then I saw MNG and knew that they were FEDEX's domestic partner in Turkey. Six months ago I never paid attention to these companies. Now I have a new perspective. Let me put it this way, "I used to look now I see."

I liked the way the cases were grouped. Reading about Ford and Toyota, Apple and Dell, UPS and FedEx and their different management approaches were amazing.

\subsection{Case Discussions}

Most students acknowledged the merits of case discussions. The discussion phase lies in the heart of the case based methodology. Students explained that the discussions held in class were very useful since they were exposed to different ways of thinking. Some students expressed their views as:

The discussions were so useful in class. It was so interesting to see how my friends approached a problem and how they analyzed it.

This is the only course, that we kept discussing the cases with my friends even after class. 
I learned all the theories and concepts so well through case discussions that I even helped my roommate who studies management in a different university with his term paper.

Definitely a methodology that focuses on learning and retention. You just don't learn one idea but many ideas during discussions.

If we just learned the theories of management through lecturing I don't believe I would have remembered any of it in two months. Now that I have watched the documentaries, discussed the cases with my friends in class, I'll always remember them.

\subsection{Views on Class Presentations}

The students were asked to form groups and choose a company of their choice and present the company as a case study to the class at the end of the semester. They were handed out an outline of the management concepts and approaches to study and other topics they could apply to their company depending on the market it was operating in. Most of the groups chose popular social networks and online companies that they were familiar with and used on daily basis, such as Facebook, Twitter, Google, and Amazon.

Our own choice of company presentation was a great way to apply what we have learned throughout the semester. It was a great experience.

Some of my friends' presentations were so good that I'm planning on keeping them as they might come handy in the future when I'm a manager.

My classmates' presentations were awesome. Since most them were technology companies, I learned a lot from them. Most were companies we all knew very well but at the same time we realized that we didn't know anything about them. I would like to attend next year's students' presentations as well.

\subsection{Language Barriers}

One of the challenges some students faced were their lack of English in understanding the cases. Since management is a non-departmental course for the computer engineering students it probably is one of the most intensive courses that they do a lot reading in English. Below are the statements made by two students explaining this:

I had problems with this course because all the materials were in English and there were a lot of readings. My English is not very good and I had difficulty from time to time understanding the cases.

I wish our department's education was not in English. I would have understood everything better if the language was in Turkish.

On the contrary, some students specifically mentioned that the cases helped them a lot in learning new vocabulary. Some stated:

I learned a lot of new vocabulary in English.

I definitely learned a lot of new expressions in English and I feel like I can talk more fluently.

I'm glad this class was in English. I loved reading the cases in English. It definitely improved my language skills.

\section{Discussion}

The goal of this study was to determine whether the case based learning, which is a different format than the traditional lecturing, for teaching management to non-business students (computer engineering students) is an effective way to help them learn management concepts and practices. In the study the students noted that their education in their department was mostly theoretical and for most of them this was their first time that a course was based on case-based learning. However, the transition was not difficult and the students stated that they enjoyed the cases as well as the discussions in class. They liked the fact that they were able to participate in class that made the course more interactive and participatory and that different ideas from their classmates also gave them a new understanding on how to analyze a given problem or situation. One of the interesting findings was that some students stated that they have taken a case based course before. However, this may not be the actual case. The computer engineering department does not offer a management course prior to this class or have other courses based on case methodology in their freshman or sophomore year. They may have confused the methodology with another critical thinking and problem solving class they may have previously taken.

The success of the case method depends, to a large extent, on the type of cases used. The students ranking of the cases they liked most is important to reflect on. Their top pick was the 'Fordism' case that they studied with the 
case 'Changing ways of making cars'. The Fordism case was supported by the BBC documentary, People's Century, 'On the Line' episode. In this film they learned who Henry Ford was and how he uses Taylorism, division of labor, and the assembly line to manufacture automobiles. These were the first cases they studied and it was an introduction of the development of mass production. The students seemed to have found the first assembly line to be very interesting. Looking back a hundred years and studying how things have changed since then might have caught their attention. It is assumed that this one hour long documentary have helped them visualize the changes which took place with the introduction of mass production. The results reveal that the students have found the Fordism case more interesting than Apple or Dell. One would expect that computer engineering students would prefer both of these cases more than Ford since they are very popular and are companies that are closely linked to their department. The students also ranked McDonald's and Levi's among the most interesting cases discussed in class. The assumption would be that they eat from McDonald's and they wear jeans (not necessarily Levi's) and that both companies have high brand awareness among university students.

Students were asked to state what they liked and were invited to write their comments on what could be done to improve the course. Two students stated:

Simulation cases could also be given where we can work online and compare each others' status. We could compare our companies' position with different decisions made by other friends' companies.

May be the professor could have asked us to write a software program, like a simulation game, where we could establish a firm, with a product, in a market and sell it to customers. I would love to create a game as such.

Simulation cases are also a type of case-based learning method that you can work online. The students' suggestions shows that they now have a higher level of applying their computer engineering skills with management which reflects that they have learned the introduced and discussed concepts thoroughly and now can come up with new ideas. Simulation cases were not given at this course since this was an introductory management principles course.

The students loved the cases where there were brief summaries of the companies' owners' backgrounds. They particularly were interested in Steve Jobs and Michael Dell as both were market leaders in the technology sector. One student suggested:

I wish there were more cases like Apple and Dell that are related to our department.

The ultimate goal is for the students to understand the concepts of management through case-based learning and provide examples of real-business situations on how the concepts are applied.

\section{Conclusion}

One could ask the question "Why use the case method?" to teach non-business students an introductory management course. Gill (2011) states that the answer depends mainly on what you believe about the world you are studying. If you believe that the world is governed by a manageably small set of straightforward principles that are awaiting discovery than it would be hard to recommend the exertion required to employ the paradigm. Yet, if you believe that the world you are studying is truly complex then the case method is one of the best approaches to better understand that what is available to you. Cases make a systematic attempt to gather and synthesize all the information that is available to the investigator and offer the student a chance to explore a type of situation they may likely encounter in practice(Gill, 2011). Using the case method to teach management to computer engineering students seem to suit well since it is a very fast changing and complex environment that they are studying in such as technology.

The study revealed that the case based methodology is an effective teaching tool for an introductory management course for non-business students. The students' have gained a new perspective and understanding and developed an interest in the business world. One of the advantages of the case based method is that it bridges the gap between theory and the real world (Asbugh \& Kasten, 1995). The results indicate that after taking this management course the students were very interested in the business practices and were able to understand the functions of real companies. Results of the students' responses reveal that the benefits of class discussions actively engage the students in the learning process. They stated that the discussions held in class were very useful and exposed them to different ways of thinking. The interactions during discussions help the students gain exposure to alternative perspectives and promote development of deep learning (Garrison \& Vaughn, 2008). This experience was found beneficial and added value to their course. It is clear that case based teaching method motivates the students and contributes to their learning experience. The students also offered some suggestions such as to use simulation cases where they can virtually manage a company. The results 
suggest that the availability of good cases is the key to effective teaching. It helps the students to engage for the deeper understanding of concepts. The case teaching seems particularly effective to equip students with not only basic management theories but practical abilities as well.

Using the exploratory approach this study attempted to identify the use of case based methodology in a management course with non-business students. The findings highlight that the case method helped the non-business students to develop an interest in business. On a positive note, most students expressed that they preferred this method to a traditional lecture course. While there are limitations to the small sample size of the study it still sheds light on the process at work here. It is hoped that this study encourages the design and development of case based management courses for other non-business students in the future as well as other future research projects. Expanding the sample of students and the context of the study to new research studies would be helpful to support the existing findings, and expand data analysis to other significant variables that can explain the perceived effectiveness of case base methodology in different student groups.

\section{References}

Ambrosini, V., Bowman, C., \& Collier, N. (2010). Using teaching case studies for management research. Strategic Organization, 8(3), 206-229. http://dx.doi.org/10.1177/1476127010374254

Asbaugh, C., \& Kasten, K. (1995). Educational leadership: Case studies for reflective practice. NY: Longman.

Ates, O. (2012). Impact of case study method on an ESP business course. International Journal of Business and Social Science, 3(6), 135-140.

Bogdan, B. (2008). Using strategic management study cases in Romania. Annals of the University of Oradea, Economic Science Series, 4(1), 61-65.

Breslin, M., \& Buchanan, R. (2008). On the case study method of research and teaching in design. Massachusetts Institute of Technology Design Issues, 24(1), 36-40. http://dx.doi.org/10.1162/desi.2008.24.1.36

Chakrabati, D., \& Balaji, M. S. (2007). Perception of Faculty on Case Study Method of Teaching in Management Education: An Empirical Study. The Icfaian Journal of Management Research, 6(10), 7-22.

Chen, L., Zhao, H., \& Ding, C. (2009). A study on difficulty applicability and teaching forms of management case teaching in undergraduates. International Journal of Business and Management, 4(11), 18-23.

Christensen, C. M., \& Carlile, P. R. (2009). Course research: Using the case method to build and teach management theory. Academy of Management Learning and Education, 8(2), 240-251. http://dx.doi.org/10.5465/AMLE.2009.41788846

Cochran, J. J. (2000). Introductory business or cases: successful use of cases in introductory undergraduate business college operational research courses. Journal of the Operational Research Society, 51, 1378-1385.

Garvin, D. (2007). Teaching executives and teaching MBAs: Reflections on the case method. Academy of Management Learning and Education, 6(3), 364-374. http://dx.doi.org/10.5465/AMLE.2007.26361626

Garrison, D. R., \& Vaughn, N. D. (2008). Blended learning in higher education: Framework, principles and guidelines. New York: John Wiley and Sons.

Gill, T. G. (2011). Informing with the case method: A guide to case method research, writing and facilitation. Santa Rosa, CA: Informing Science Press.

Grosse, C.U. (1988). The case study approach to teaching business English. English for Specific Purposes, 7(2), 131-136. http://dx.doi.org/10.1016/0889-4906(88)90031-2

Gurau, C. (2010). Teaching marketing strategy through case studies: Empirical observations. The International Journal of Learning, 16(12), 439-449.

Jackson, J. (1998). Reality-based decision cases in ESP teacher education: Windows on practice. English for Specific Purposes, 23(3), 213-232. http://dx.doi.org/10.1016/j.esp.2003.05.001

Kvam, P. (2000). The effect of active learning methods on student retention in engineering statistics. American Statistician, 54(2), 136-140.

Liang, N., \& Wang, J. (2004). Implicit mental models in teaching cases: an empirical study of popular MBA cases in the United States and China. Academy of Management Learning and Education, 3(4), 397-413. http://dx.doi.org/10.5465/AMLE.2004.15112545

Menna, A. (2009). The business case method: An examination of 2009 case competition. Management in 
Education, 24(2), 74-79. http://dx.doi.org/10.1177/0892020610363094

Meyer, C., \& Jones, T. B. (1993). Promoting active learning: Strategies for the college classroom. San Francisco: Jossey-Bass.

Miller, D., \& Friesen, P. (1977). Strategy making in context: Ten empirical archetypes. Journal of Management Studies, 14(3), 253-280. http://dx.doi.org/10.1111/j.1467-6486.1977.tb00365.x

Pariseau, S. E., \& Kezim, B. (2007). The effect of using case studies in business statistics. Journal of Education for Business, 83(1), 27-31. http://dx.doi.org/10.3200/JOEB.83.1.27-31

Peterson, R., \& Pratt, E. (2004). The history sphere in MBA, marketing instruction: An application. Marketing Education Review, 14(2), 55-67.

Sanchis, C. M. (2007). The case study method: a powerful teaching tool in sports marketing education. International Journal of Sports Marketing and Sponsorship, 9(1), 7-10.

Shugan, S. C. (2006). Save research-Abandon the case method of teaching. Marketing Science, 25(2), 109-115. http://dx.doi.org/10.1287/mksc.1060.0202

Spackman, A., \& Camacho, L. (2009). Rendering information literacy relevant: A case-based pedagogy. Journal of Academic Librarianship, 35(6), 548-554. http://dx.doi.org/10.1016/j.acalib.2009.08.005

Tang, L. P., \& Austin, M. J. (2009). Students' perceptions of teaching technologies, application of technologies, and academic performance. Computers \& Education, 53(4), 1241-1255. http://dx.doi.org/10.1016/j.compedu.2009.06.007

\section{Appendix}

\section{Student Survey}

1. Please state:

Age:

Gender: Female ( ) Male ( )

Hometown:

2. In learning the concepts, theories and practices of management, the case based methodology has been

( ) Very useful

() Somewhat useful

( ) Not very useful

( ) Not useful at all

3. To understand the different practices and applications in the business world by companies through case based methodology has been

() Very useful

( ) Somewhat useful

() Not very useful

( ) Not useful at all

4. After completing this management course I have developed an interest in the business world and different companies' functions.

( ) Very

() Somewhat

() Not very

() Not at all 
5. Do you believe you have gained a new perspective and understanding of the business news?

() Yes

( ) No

6. Would you prefer a course solely based on lecturing rather than the case based methodology?

() Yes

() No

7. Please state the top three cases that you liked and were interested in studying the most.

(1)

(2)

(3)

8. Did you take a case based course before?

() Yes

( ) No

9. What are you personal opinions of taking the management course based on cases?

10. Are you content with this management course which was based on case methodology? What different approaches would you suggest? Please feel free to comment on anything related to the course. 